Research Paper

\title{
The value of neutrophil-to-lymphocyte ratio for response and prognostic effect of neoadjuvant chemotherapy in solid tumors: A systematic review and meta-analysis
}

\author{
Xuan Li”, Danian Dai\#, Bo Chen" ${ }^{\#}$, Hailin Tang, Xiaoming Xie ${ }^{\bowtie}$, Weidong Wei ${ }^{\bowtie}$ \\ Department of Breast Oncology, Sun Yat-Sen University Cancer Center, State Key Laboratory of Oncology in South China, Collaborative Innovation Center for \\ Cancer Medicine, 651 East Dong feng Road, Guangzhou, 510060, China \\ \#Contribute equally \\ $\triangle$ Corresponding author: Weidong Wei: telephone and FAX: 020-38523701 Email: weiwd@sysucc.org.cn and Xiaoming Xie: telephone and FAX: 020-38522636 \\ Email: xiexm@sysucc.org.cn \\ (C) Ivyspring International Publisher. This is an open access article distributed under the terms of the Creative Commons Attribution (CC BY-NC) license \\ (https://creativecommons.org/licenses/by-nc/4.0/). See http://ivyspring.com/terms for full terms and conditions.
}

Received: 2017.09.27; Accepted: 2018.01.28; Published: 2018.02.12

\begin{abstract}
Introduction: The neutrophil-to-lymphocyte ratio (NLR) has been found to be an indicator of poor prognosis in many tumour types. However, little is known about the relationship between the NLR and patients with tumours who receive neoadjuvant chemotherapy (NAC) in terms of response rate and prognostic ability. We thus performed this meta-analysis to further investigate this relationship.

Methods: An electronic systematic literature search for articles published before September 2017 was performed to explore the association between the pretreatment NLR and outcome in patients treated with NAC. Data were extracted by the reported odds ratios (ORs) and hazard ratios (HRs) with their $95 \%$ confidence intervals $(\mathrm{Cls})$ for the response rate and the survival outcome, respectively. The results were pooled using the random-effect or fixed-effect model.

Results: Thirty-three studies were eventually included in our study, and all were published no earlier than 2011. An NLR that was higher than the cut-off was associated with a lower pathological complete response $(P C R)$ rate in patients with cancer $(O R=1.72,95 \% \mathrm{Cl}, 1.26-2.33)$. A lower NLR was associated with better overall survival $(\mathrm{OS})(\mathrm{HR}=1.58,95 \% \mathrm{Cl}, 1.34-1.86)$, cancer-specific survival (CSS) $(\mathrm{HR}=2.22,95 \% \mathrm{Cl}, 1.32-3.74)$, disease-free survival $(\mathrm{DFS})(\mathrm{HR}=1.32,95 \% \mathrm{Cl}$, 1.10-1.59) and recurrence-free survival (RFS) ( $\mathrm{HR}=1.90,95 \% \mathrm{Cl}, 1.50-2.40)$.

Conclusion: Overall, an NLR lower than the cut-off value indicated a greater chance for $\mathrm{PCR}$ and may predict good survival outcomes after NAC for patients with solid tumours. The use of the NLR for risk stratification before NAC should be further demonstrated by future large-scale prospective studies.
\end{abstract}

Key words: Neutrophil to lymphocyte ratio (NLR); prognosis; solid cancer; neoadjuvant therapy; meta-analysis

\section{Introduction}

Neoadjuvant chemotherapy or chemoradiation therapy plays an important role in the treatment of locally advanced cancer. In bladder cancer, platinum-based combination neoadjuvant chemotherapy has shown obvious improvements in survival, and the Canadian Association of Genitourinary Medical Oncologists (CAGMO) reached a consensus with respect to the use of neoadjuvant chemotherapy in muscle invasive bladder cancer to improve patient outcomes[1, 2]. Neoadjuvant chemotherapy regimens 
used in breast cancer not only increased the rate of breast-conserving surgery but also reduced the risk of some negative outcomes[3]. It is well known that the significantly improved outcome in patients is closely associated with pathological complete response (pCR) after NAC[4,5]. Researchers have proposed the use of many markers, such as mutated genes, that are associated with the response to neoadjuvant treatment $[6,7]$. However, those markers are not easily assessable, and until now, no proven clinical biomarkers have been widely accepted to predict the tumour response after NAC. Therefore, an accurate marker is needed as it can prevent futile chemotherapy in patients so that they can receive definitive surgery in time.

Currently, increasing evidence shows that tumour-associated inflammation may be associated with systemic inflammation and may play an important role in cancer development, survival and chemo-sensitivity[8-12]. Inflammation affects blood parameters first, and abnormalities in blood cells such as neutrophilia and lymphopenia have been found in patients with tumours. The neutrophil-to-lymphocyte ratio (NLR) is an easily available and inexpensive marker of inflammation, and an elevated NLR has been used as a marker of poor prognosis in many tumours[13]. Some studies have explored the crosstalk between inflammation and chemosensitivity in cancer patients and found that a low NLR may be associated with a high response to NAC $[14,15]$. The direct impact of the NLR on the survival of patients after NAC remains inconclusive.

One aim of our meta-analysis was to study the level of pretreatment NLR and its relationship to the pathologic complete response to NAC in patients with solid tumours. The other aim was to evaluate the prognostic value of NLR with respect to the survival outcome in cancer patients after NAC by pooling the eligible results.

\section{Methods}

\section{Search strategy}

This meta-analysis was conducted according to the guidelines of the Preferred Reporting Items for Systematic Reviews and Meta-Analyses (PRISMA) statement. Relevant articles published until September 2017 were identified through searches of PubMed, Embase and the Web of Science. The related keywords used were "tumour" OR "cancer" OR "neoplasm" AND "neoadjuvant chemotherapy" OR "preoperative chemotherapy" OR "primary chemotherapy" AND "neutrophils" AND "lymphocyte" AND "ratio". Other references from previously published studies were also searched.

\section{Study selection}

Two independent authors selected the identified studies. The inclusion criteria were as follows: (1) Studies that involved patients with solid tumours who received neoadjuvant chemotherapy or neoadjuvant chemoradiation and that reported the prognostic impact of the peripheral blood NLR; in these studies, the NLR appeared as a categorical variable. (2) Studies that provided the relationship between the NLR and $\mathrm{pCR}$ after neoadjuvant treatment as odds ratios (ORs) with 95\% confidence intervals (CIs) or studies that provided data on the number of patients who achieved pCR in the low and high NLR groups. The definition of $\mathrm{pCR}$ was classified as the complete absence of cancer tissue in all postoperative material. (3) Studies that provided survival data such as overall survival (OS), cancerspecific survival (CSS), disease-free survival (DFS), progression-free survival (PFS) and recurrencefree survival (RFS) in the form of hazard ratios (HRs) with $95 \%$ confidence intervals (CIs). The definitions of DFS and PFS were similar and can be combined in an analysis. (4) If duplicate or overlapping data appeared, the study report with the most samples and comprehensive information was included. (5) Abstracts from which useful information could be extracted and those with clear treatment methods were also included.

\section{Data extraction}

Two reviewers independently extracted the useful data from the eligible studies. The following information was gathered: first author's name, publication year, publication type, tumour type, research region, entire sample size, the cut-off value of the NLR, the methods by which the NLR was obtained, neoadjuvant treatment methods, neoadjuvant treatment response information, and survival outcome types. The results of multivariable analyses were given precedence, but otherwise, the results of univariate analyses were extracted.

\section{Quality assessment}

The quality of the included studies was assessed using the Newcastle-Ottawa Scale (NOS) tool. The NOS tool included three main domains: study selection (0-4 points), comparability (0-2 points) and results assessments (o-4 points). Studies were rated as high quality if the NOS scored six or higher, otherwise rated as low quality. Two independent authors performed this work, and any discrepancies were resolved by discussion.

\section{Statistical analyses}

We used RevMan 5.3 (The Cochrane Collabora- 
tion, Copenhagen, Denmark) to pool the results of our meta-analysis. The $\mathrm{pCR}$ values and the total number of patients in the low and high NLR groups were extracted to calculate the ORs and 95\% CIs; then, these results were pooled with other ORs that were provided directly to obtain the final results. A pooled OR $>1$ frequently indicated that a low NLR was related to a relatively better $\mathrm{pCR}$ rate. The HR was representative of the high blood NLR over the low blood NLR. HRs $>1$ implied a poor prognosis while HRs $<1$ implied a good prognosis. Heterogeneity was assessed using Cochran $Q$ ( $p$ value for heterogeneity) and $\mathrm{I}^{2}$ statistics. An $\mathrm{I}^{2}>50 \%$ or a $\mathrm{p}<0.1$ indicated significant heterogeneity then a random-effect model was used, but otherwise, a fixed-effect model was used. Subgroup analyses were performed according to our data features such as publication type, research region, tumour type, and cut-off NLR values, among others, to determine the potential source of heterogeneity.

Publication bias was assessed by Egger's test and $\mathrm{P}>|\mathrm{t}|<0.05$ indicated significant publication bias. When publication bias existed, trim-and-fill methods were applied by adding the missing studies to the meta-analysis, and the new pooled results were recalculated to adjust the primary results. These analyses were performed using StataSE (StataCorp, College Station, TX, USA) software.

\section{Results}

\section{Study characteristics}

In summary, 1167 records were identified, from which 33 records met all our criteria and finally included in our meta-analysis. All the enrolled studies were published between 2011 and 2017, and 27 contained full-text data, while 6 contained supplemental abstract data (Figure 1). In all, 6243 individuals were included in the analysis with a sample size that ranged from 41 to 845 . Five studies on bladder cancer[16-20], eight on breast cancer[15, 21-27], twelve on rectal cancer[28-39], six on gastroesophageal cancer[40-45], one on head and neck squamous cell carcinoma[46] and one on intrahepatic cholangio carcinoma[47]. Eighteen studies reported the relationship between the NLR and pCR, and twenty-four studies reported the association between the NLR and outcomes (OS, CSS, DFS, RFS) in patients who received NAC. The cut-off value of the NLR was reported in 32 studies but was unclear in one study (Table 1).

\section{Relationship between the NLR and pCR}

Eighteen studies reported the relationship between the NLR and pCR. A lower NLR was associated with a higher $\mathrm{pCR}$ rate $(\mathrm{OR}=1.72,95 \% \mathrm{CI}$,
1.26-2.33, $\mathrm{I}^{2}=66 \%$, random effect model; Figure 2). Bladder cancer, breast cancer and rectal cancer were the three most common tumour types involved, and among them, bladder cancer $(\mathrm{OR}=1.95,95 \% \mathrm{CI}$, $\left.1.16-3.29, \mathrm{I}^{2}=0 \%\right)$ and rectal cancer $(\mathrm{OR}=2.01,95 \%$ $\left.\mathrm{CI}, 1.14-3.55, \mathrm{I}^{2}=55 \%\right)$ demonstrated statistical significance, while breast cancer did not demonstrate statistical significance $\left(\mathrm{OR}=1.41,95 \% \mathrm{CI}, 0.91-2.19\right.$, $\mathrm{I}^{2}$ $=68 \%$ ). A stratified analysis using data from the full-texts or abstracts showed that a low NLR from the full-texts was significantly associated with the $\mathrm{pCR}$ rate $(\mathrm{OR}=1.91,95 \% \mathrm{CI}, 1.28-2.84)$; however, a low NLR from the abstracts was not significantly associated with the $\mathrm{pCR}$ rate $(\mathrm{OR}=1.35,95 \% \mathrm{CI}$, $0.88-2.07)$. When the data were stratified according to the geographic region, for research conducted in Asia $(\mathrm{OR}=1.82,95 \% \mathrm{CI}, 1.18-2.81)$ and the North America $(\mathrm{OR}=1.64,95 \% \mathrm{CI}, 1.03-2.61)$, the NLR data were significantly associated with the pCR rate, while for the studies conducted in Europe, the data $(\mathrm{OR}=1.73$, 95\% CI, 0.92-3.27) did not show a statistical association. For the different NLR cut-off values, NLR values higher than 3 showed an obvious association between the NLR and the $\mathrm{pCR}(\mathrm{OR}=3.00,95 \% \mathrm{CI}$, 1.48-6.12). In contrast, values equal to $3(\mathrm{OR}=1.52$, 95\% CI, 0.95-2.44) or lower than 3 (OR $=1.64,95 \% \mathrm{CI}$, $0.97-2.77$ ) did not show a significant association between the NLR and the pCR (Table 2).

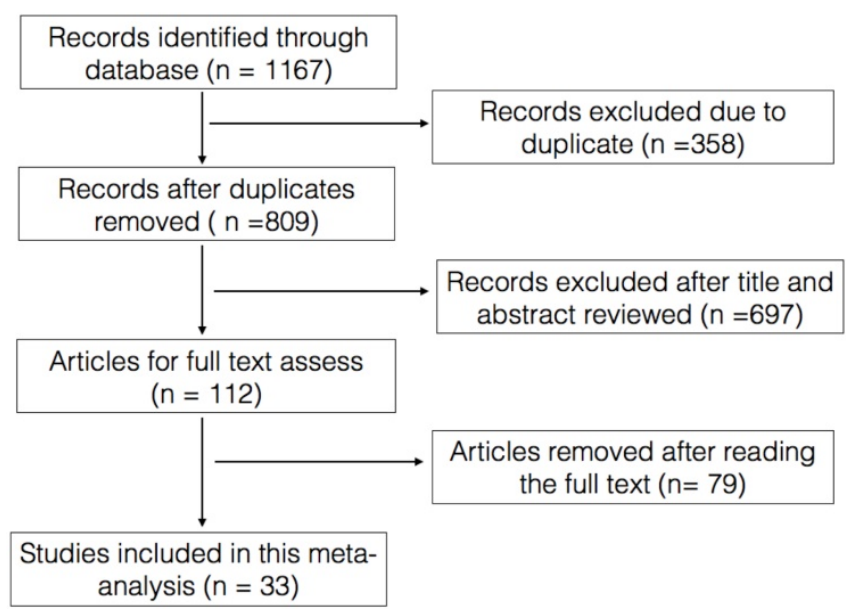

Figure 1. Flow chart of the study search.

\section{Overall survival}

Eighteen studies reported HRs for overall survival. Higher NLRs were associated with a poor OS $\left(\mathrm{HR}=1.58,95 \% \mathrm{CI}, 1.34-1.86, \mathrm{I}^{2}=77 \%\right.$; Figure 3 (a)). The pooled results of the NLRs for OS among the tumour subgroups showed a statistical association with OS in rectal cancer $(\mathrm{HR}=1.93,95 \% \mathrm{CI}, 1.17-3.19)$ and other unselected tumours $(\mathrm{HR}=3.04,95 \% \mathrm{CI}$, 1.64-5.64), while in bladder cancer $(\mathrm{HR}=1.52,95 \% \mathrm{CI}$, 
0.97-2.36), breast cancer $(\mathrm{HR}=2.26,95 \% \mathrm{CI}, 0.82-6.28)$ and gastroesophageal cancer $(\mathrm{HR}=1.36,95 \% \mathrm{CI}$, 0.99-1.85), the prognostic effect of the NLR on OS was not statistically significant. A subgroup analysis by research region revealed that the prognostic effect of the NLR was lowest in Europe $(\mathrm{HR}=1.18,95 \% \mathrm{CI}$, 1.01-1.38), followed by Asia $(\mathrm{HR}=1.65,95 \% \mathrm{CI}$, 1.15-2.35) and was highest in North America (HR =
2.03, 95\% CI, 1.59-2.59). A higher cut-off of the NLR showed a higher prognostic effect of the NLR, whereas an NLR lower than 3 with an HR $=1.46$ (95\% CI, 1.14-1.87), an NLR equal to 3 with an HR $=1.55$ (95\% CI, 1.16-2.07) and an NLR higher than 3 with an $\mathrm{HR}=2.31$ (1.20-4.43). Specific data regarding the subgroup analysis are shown in Table 2.

Table 1: Baseline characteristics of included studies.

\begin{tabular}{|c|c|c|c|c|c|c|c|c|c|c|c|}
\hline Author & $\begin{array}{l}\text { Publish } \\
\text { year }\end{array}$ & $\begin{array}{l}\text { Publish } \\
\text { type }\end{array}$ & Tumor type & Country & $\begin{array}{l}\text { Sample } \\
\text { size }\end{array}$ & $\begin{array}{l}\text { NLR } \\
\text { cut-off }\end{array}$ & $\begin{array}{l}\text { Method } \\
\text { for NLR } \\
\text { cut-off } \\
\text { value } \\
\text { chose }\end{array}$ & $\begin{array}{l}\text { Neoadjuvant } \\
\text { treatment type }\end{array}$ & $\begin{array}{l}\text { Response } \\
\text { rate } \\
\text { reported } \\
\text { (yes/no) }\end{array}$ & $\begin{array}{l}\text { Types } \\
\text { of } \\
\text { outcome } \\
\text { reported }\end{array}$ & $\begin{array}{l}\text { NOS } \\
\text { score }\end{array}$ \\
\hline Buisan & 2017 & full & Muscle-invasive Bladder cancer & German & 75 & 2.5 & ROC & chemotherapy & yes & $\begin{array}{l}\text { PFS, } \\
\text { CSS, OS }\end{array}$ & 7 \\
\hline Kessel & 2016 & full & Muscle-invasive Bladder cancer & Netherlands & 123 & 2.21 & $\mathrm{ROC}$ & chemotherapy & yes & NA & 8 \\
\hline Leibowitz-Amit & 2016 & full & Muscle-invasive Bladder cancer & Israel & 55 & 3 & NA & chemotherapy & yes & NA & 8 \\
\hline Mmeje & 2016 & Abstract & Bladder cancer & American & 584 & 4.9 & $\begin{array}{l}\text { CART } \\
\text { models }\end{array}$ & chemotherapy & no & CSS, OS & 6 \\
\hline Siano & 2016 & Abstract & Muscle-invasive Bladder cancer & American & 272 & 3 & NA & chemotherapy & no & PFS, OS & 5 \\
\hline Asano & 2015 & full & Triple-negative breast cancer & Japan & 61 & 3 & NA & chemotherapy & yes & DFS, OS & 8 \\
\hline Chen Y & 2016 & full & Breast cancer & China & 215 & 2.1 & ROC & chemotherapy & yes & $\begin{array}{l}\text { RFS, } \\
\text { CSS }\end{array}$ & 8 \\
\hline Enriquez & 2017 & Abstract & Triple-negative breast cancer & Peru & 338 & 3 & NA & chemotherapy & yes & DFS, OS & 6 \\
\hline Hernandez & 2017 & full & Breast cancer & Spain & 150 & 3.33 & ROC & chemotherapy & yes & NA & 7 \\
\hline Koh & 2014 & full & $\begin{array}{l}\text { ER positive and/or PR positive } \\
\text { and HER2-negative breast } \\
\text { cancer }\end{array}$ & Korea & 157 & 2.25 & ROC & chemotherapy & yes & RFS, OS & 9 \\
\hline McGuire & 2017 & Abstract & Breast cancer & Ireland & 211 & 3 & NA & chemotherapy & yes & NA & 5 \\
\hline Suppan & 2015 & full & Breast cancer & Austria & 247 & NA & NA & chemotherapy & yes & DFS & 8 \\
\hline $\mathrm{Xu}$ & 2017 & full & Breast cancer & China & 128 & 1.67 & ROC & chemotherapy & yes & NA & 7 \\
\hline Caputo & 2016 & full & Rectal cancer & Italy & 87 & $2.8 / 3.8$ & ROC & chemoradiation & yes & NA & 7 \\
\hline Carruthers & 2012 & full & Locally advanced rectal cancer & UK & 115 & 5 & $\begin{array}{l}\text { Pre-search } \\
\text { data }\end{array}$ & chemoradiation & no & OS, DFS & 8 \\
\hline Dudani & 2017 & Abstract & Local advanced rectal cancer & Canada & 845 & 4 & NA & chemoradiation & yes & NA & 6 \\
\hline Hodek & 2016 & full & Local advanced rectal cancer & Czech & 173 & 2.8 & $x^{2}$ text & chemoradiation & no & OS & 7 \\
\hline Kim & 2014 & full & Rectal cancer & Korea & 102 & 3 & Experience & chemoradiation & yes & $\begin{array}{l}\text { RFS, } \\
\text { CSS }\end{array}$ & 7 \\
\hline krauthamer & 2013 & full & Advanced rectal cancer & Israel & 140 & 5 & ROC & chemoradiation & yes & NA & 7 \\
\hline Lee & 2017 & full & Local advanced rectal cancer & Korea & 291 & 5 & NA & chemoradiation & yes & NA & 8 \\
\hline Nagasaki & 2015 & full & $\begin{array}{l}\text { locally advanced low rectal } \\
\text { cancer }\end{array}$ & Japan & 140 & 3 & ROC & chemotherapy & yes & OS, RFS & 8 \\
\hline Runau & 2017 & full & Local advanced rectal cancer & UK & 277 & 4.32 & ROC & chemoradiation & yes & OS & 7 \\
\hline Shen J & 2017 & full & Local advanced rectal cancer & China & 202 & 3 & ROC & chemoradiation & yes & OS,DFS & 8 \\
\hline Shen L & 2014 & full & Local advanced rectal cancer & China & 199 & 2.8 & ROC & chemoradiation & no & OS, DFS & 8 \\
\hline Sung & 2017 & full & Local advanced rectal cancer & Korea & 49 & 1.75 & $\begin{array}{l}\text { The } \\
\text { maximally } \\
\text { selected } \\
\text { log-rank } \\
\text { test in } \mathrm{R} \\
\text { version }\end{array}$ & chemoradiation & yes & DFS & 7 \\
\hline Aziz & 2014 & full & Locally advanced gastric cancer & Egypt & 70 & 3 & NA & chemotherapy & no & PFS, OS & 7 \\
\hline Chen L & 2017 & full & Advanced gastric cancer & China & 91 & 2.17 & ROC & chemotherapy & yes & DFS, OS & 8 \\
\hline Jin & 2017 & full & Advanced gastric cancer & China & 119 & 2.23 & ROC & chemotherapy & no & RFS, OS & 7 \\
\hline Ji & 2016 & full & $\begin{array}{l}\text { Local advanced esophageal } \\
\text { cancer }\end{array}$ & China & 41 & 5 & NA & chemotherapy & no & $\begin{array}{l}\text { CSS, } \\
\text { PFS }\end{array}$ & 8 \\
\hline Miyata & 2011 & full & Esophageal cancer & Japan & 152 & 4 & NA & chemotherapy & no & OS & 7 \\
\hline Salih & 2016 & Abstract & $\begin{array}{l}\text { Oesophageal/gastroesophageal } \\
\text { junction }(\mathrm{O} / \mathrm{GOJ}) \\
\text { adenocarcinoma }\end{array}$ & UK & 368 & 3 & NA & chemotherapy & no & OS & 6 \\
\hline Rosculet & 2017 & full & $\begin{array}{l}\text { Head and neck squamous cell } \\
\text { carcinoma }\end{array}$ & American & 123 & 2.7 & $\begin{array}{l}\text { Median } \\
\text { value }\end{array}$ & chemoradiation & no & OS, RFS & 7 \\
\hline Omichi & 2017 & full & $\begin{array}{l}\text { Intrahepatic } \\
\text { cholangiocarcinoma }\end{array}$ & American & 43 & 3 & NA & chemotherapy & no & RFS, OS & 8 \\
\hline
\end{tabular}

Abbreviations: NLR: neutrophil-to-lymphocyte ratio; NOS: Newcastle-Ottawa Scale; OS: overall survival; CSS: cancer special survival; DFS: disease-free survival; RFS: recurrence-free survival; NA: not available; ROC: receiver operating characteristic curve. 


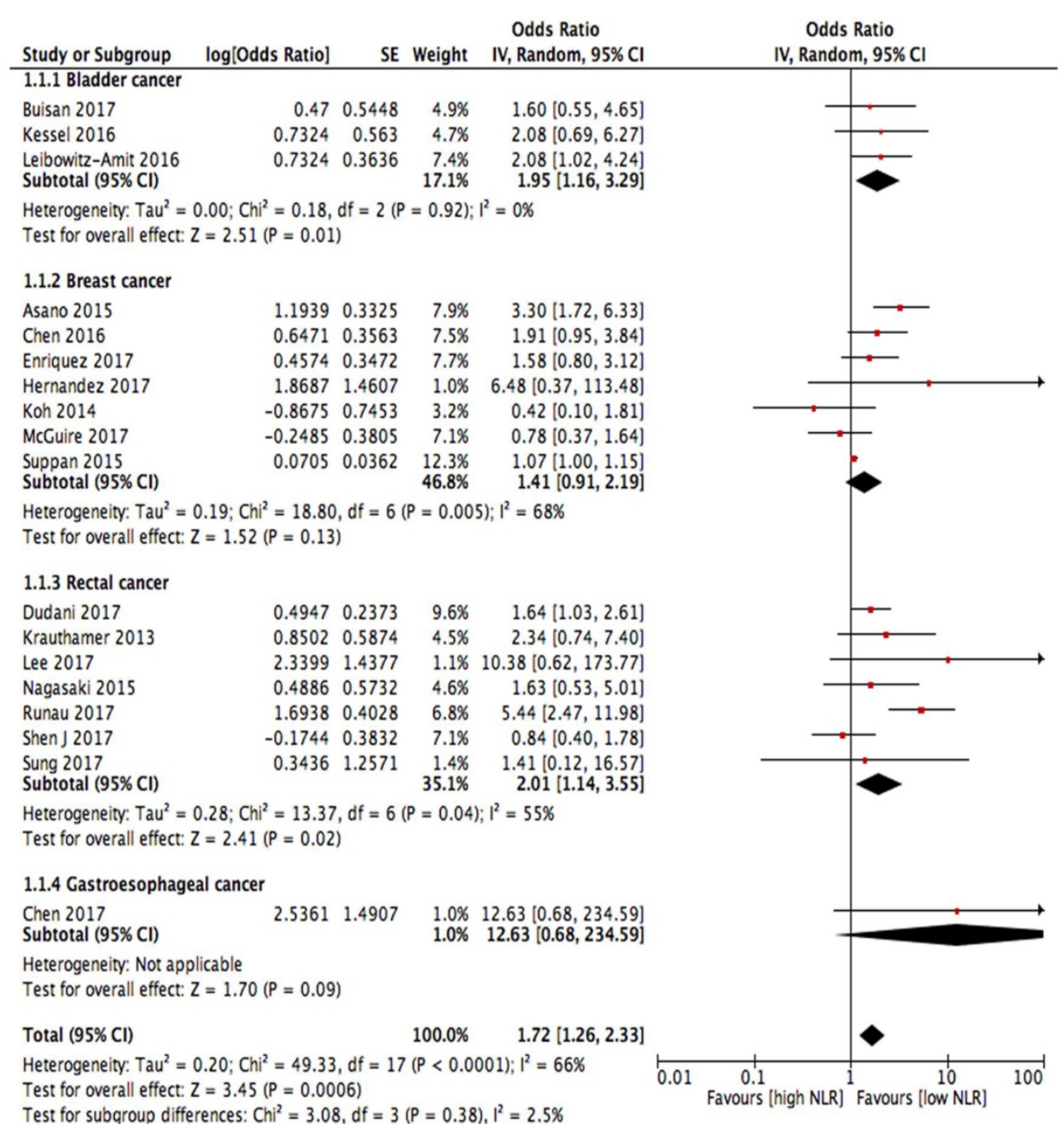

Figure 2. Forest plots for association between NLR and $p C R$.

\section{Cancer-specific Survival}

Only five studies reported the HRs for CSS. Two studies examined bladder cancer, one examined breast cancer, one examined oesophageal cancer and one examined rectal cancer. A higher NLR was associated with poor CSS in all five studies. The pooled HR for CSS was 2.22 (95\% CI, 1.32-3.74; Figure 3 (b)) with significant heterogeneity $\left(\mathrm{I}^{2}=81 \%\right)$ using a random effect model.

\section{Disease-Free survival}

Eleven studies reported DFS data. Overall, a lower NLR was associated with higher DFS $(\mathrm{HR}=$ $1.32,95 \%$ CI, $1.10-1.59$, $\mathrm{I}^{2}=73 \%$, random effect model; Figure 3(c)). When stratified by tumour type, only the results for bladder cancer $(\mathrm{HR}=1.32,95 \% \mathrm{CI}$, 1.08-1.61) reached statistical significance. Breast cancer $(\mathrm{HR}=1.14,95 \% \mathrm{CI}, 0.87-1.49)$, rectal cancer $(\mathrm{HR}=1.84,95 \% \mathrm{CI}, 0.94-3.60)$ and gastroesophageal cancer $(\mathrm{HR}=1.34,95 \% \mathrm{CI}, 0.76-2.36)$ all showed a non-significant association between a low NLR and a high DFS. No statistically significant difference was observed among tumour types (Pinteraction $=0.58$ ).

\section{Recurrence-Free Survival}

A total of seven records reported the hazard ratios for RFS. The pooled HR for RFS was 1.90 (95\% $\mathrm{CI}, 1.50-2.40)$ with no heterogeneity $\left(\mathrm{I}^{2}=36 \%\right.$, fixed effect model; Figure $3(\mathrm{~d})$ ).

\section{Publication Bias}

For the pCR and OS subset, the asymmetry of the funnel plot indicated potential publication bias, which was confirmed by Egger's test (all $p<0.001$ ). After adjusting the results using the trim-and-fill method, the pooled OR for pCR was $1.64(95 \% \mathrm{CI}, 1.22-2.23$; Figure $4(\mathrm{a}))$, and the pooled HR for OS was 1.37 (95\% CI, 1.16-1.62; Figure 4 (b)) according to a random effect model. The results were roughly consistent with the primary results. 
Table 2: Subgroup analyses of the associations between NLR and OS, DFS and pCR

\begin{tabular}{|c|c|c|c|c|c|c|c|c|c|c|c|c|}
\hline \multirow[t]{2}{*}{ Variables } & \multicolumn{4}{|c|}{ Overall survival (OS) } & \multicolumn{4}{|c|}{ Disease-free survival (DFS) } & \multicolumn{4}{|c|}{ pathological complete response (pCR) } \\
\hline & $\begin{array}{l}\text { No of } \\
\text { studies }\end{array}$ & $\begin{array}{l}\text { HR } \\
(95 \% \mathrm{CI})\end{array}$ & $\mathbf{I}^{2}$, Phet & Pinteraction & $\begin{array}{l}\text { No of } \\
\text { studies }\end{array}$ & $\begin{array}{l}\text { HR } \\
(95 \% \mathrm{CI})\end{array}$ & $\mathbf{I}^{2}$, Phet & Pinteraction & $\begin{array}{l}\text { No of } \\
\text { studies }\end{array}$ & OR $(95 \% \mathrm{CI})$ & $\mathbf{I}^{2}$, Phet & Pinteraction \\
\hline Total & 18 & $\begin{array}{l}1.58 \\
(1.34-1.86)\end{array}$ & $\mathrm{p}<0.0001$ & & 11 & $\begin{array}{l}1.32 \\
(1.10-1.59)\end{array}$ & $\mathrm{p}<0.0001$ & & 18 & $\begin{array}{l}1.72 \\
(1.26-2.33)\end{array}$ & $\mathrm{p}<0.0001$ & \\
\hline Publication type & & & & $p=0.63$ & & & & $\mathrm{p}=0.28$ & & & & $p=0.24$ \\
\hline Full text & 14 & $\begin{array}{l}1.70 \\
(1.34-2.16)\end{array}$ & $\mathrm{p}<0.0001$ & & 9 & $\begin{array}{l}1.27 \\
(1.03-1.55)\end{array}$ & $\mathrm{p}=0.0004$ & & 15 & $\begin{array}{l}1.91 \\
(1.28-2.84)\end{array}$ & $\mathrm{p}<0.0001$ & \\
\hline Abstract & 4 & $\begin{array}{l}1.53 \\
(1.04-2.23)\end{array}$ & $\mathrm{p}<0.0001$ & & 2 & $\begin{array}{l}1.51 \\
(1.18-1.92)\end{array}$ & $p=0.71$ & & 3 & $\begin{array}{l}1.35 \\
(0.88-2.07)\end{array}$ & $\mathrm{p}=0.23$ & \\
\hline Research region & & & & $\mathrm{p}=0.002$ & & & & $\mathrm{p}=0.74$ & & & & $p=0.98$ \\
\hline Asia & 8 & $\begin{array}{l}1.65 \\
(1.15-2.35)\end{array}$ & $p=0.05$ & & 5 & $\begin{array}{l}1.31 \\
(0.88-1.96)\end{array}$ & $\mathrm{p}=0.09$ & & 10 & $\begin{array}{l}1.82 \\
(1.18-2.81)\end{array}$ & $p=0.10$ & \\
\hline Europe & 4 & $\begin{array}{l}1.18 \\
(1.01-1.38)\end{array}$ & $p=0.002$ & & 3 & $\begin{array}{l}1.24 \\
(0.94-1.63)\end{array}$ & $\mathrm{p}<0.0001$ & & 6 & $\begin{array}{l}1.73 \\
(0.92-3.27)\end{array}$ & $\mathrm{p}=0.001$ & \\
\hline North America & 4 & $\begin{array}{l}2.03 \\
(1.59-2.59)\end{array}$ & $\mathrm{p}=0.34$ & & 1 & $\begin{array}{l}1.59 \\
(1.10-2.29)\end{array}$ & - & & 1 & $\begin{array}{l}1.64 \\
(1.03-2.61)\end{array}$ & - & \\
\hline Others & 2 & $\begin{array}{l}1.92 \\
(1.09-3.39)\end{array}$ & $p=0.22$ & & 2 & $\begin{array}{l}1.44 \\
(1.07-1.94)\end{array}$ & $\mathrm{p}=0.93$ & & 1 & $\begin{array}{l}1.58 \\
(0.80-3.12)\end{array}$ & - & \\
\hline Sample size & & & & $\mathrm{p}=0.78$ & & & & $\mathrm{p}=0.88$ & & & & $p=0.08$ \\
\hline$<100$ & 5 & $\begin{array}{l}1.57 \\
(0.99-2.49)\end{array}$ & $p=0.05$ & & 5 & $\begin{array}{l}1.37 \\
(1.03-1.83)\end{array}$ & $\mathrm{p}=0.23$ & & 5 & $\begin{array}{l}2.50 \\
(1.63-3.83)\end{array}$ & $\mathrm{p}=0.56$ & \\
\hline$>100$ & 13 & $\begin{array}{l}1.69 \\
(1.35-2.11)\end{array}$ & $\mathrm{p}<0.0001$ & & 6 & $\begin{array}{l}1.33 \\
(1.00-1.77)\end{array}$ & $\mathrm{p}=0.0006$ & & 13 & $\begin{array}{l}1.54 \\
(1.10-2.14)\end{array}$ & $p=0.001$ & \\
\hline Tumor type & & & & $p=0.19$ & & & & $\mathrm{p}=0.58$ & & & & $p=0.38$ \\
\hline Bladder cancer & 3 & $\begin{array}{l}1.52 \\
(0.97-2.36)\end{array}$ & $\mathrm{p}<0.0001$ & & 2 & $\begin{array}{l}1.32 \\
(1.08-1.61)\end{array}$ & $p=0.23$ & & 3 & $\begin{array}{l}1.95 \\
(1.16-3.29)\end{array}$ & $\mathrm{p}=0.92$ & \\
\hline Breast cancer & 3 & $\begin{array}{l}2.26 \\
(0.82-6.28)\end{array}$ & $p=0.03$ & & 3 & $\begin{array}{l}1.14 \\
(0.87-1.49)\end{array}$ & $p=0.09$ & & 7 & $\begin{array}{l}1.41 \\
(0.91-2.19)\end{array}$ & $p=0.005$ & \\
\hline Rectal cancer & 5 & $\begin{array}{l}1.93 \\
(1.17-3.19)\end{array}$ & $p=0.001$ & & 4 & $\begin{array}{l}1.84 \\
(0.94-3.60)\end{array}$ & $p=0.003$ & & 7 & $\begin{array}{l}2.01 \\
(1.14-3.55)\end{array}$ & $p=0.04$ & \\
\hline $\begin{array}{l}\text { Gastroesophageal } \\
\text { cancer }\end{array}$ & 5 & $\begin{array}{l}1.36 \\
(0.99-1.85)\end{array}$ & $\mathrm{p}=0.09$ & & 2 & $\begin{array}{l}1.34 \\
(0.76-2.36)\end{array}$ & $\mathrm{p}=0.88$ & & 1 & $\begin{array}{l}12.63 \\
(0.68-234.59)\end{array}$ & - & \\
\hline Others & 2 & $\begin{array}{l}3.04 \\
(1.64-5.64)\end{array}$ & $p=0.98$ & & - & - & - & & - & - & - & \\
\hline $\begin{array}{l}\text { Cut-off value of } \\
\text { NLR }\end{array}$ & & & & $P=0.43$ & & & & $p=0.05$ & & & & $p=0.27$ \\
\hline$<3$ & 7 & $\begin{array}{l}1.46 \\
(1.14-1.87)\end{array}$ & $p=0.005$ & & 4 & $\begin{array}{l}1.44 \\
(1.05-1.97)\end{array}$ & $\mathrm{p}=0.14$ & & 6 & $\begin{array}{l}1.64 \\
(0.97-2.77)\end{array}$ & $p=0.35$ & \\
\hline 3 & 8 & $\begin{array}{l}1.55 \\
(1.16-2.07)\end{array}$ & $p=0.002$ & & 5 & $\begin{array}{l}1.31 \\
(1.04-1.63)\end{array}$ & $\mathrm{p}=0.32$ & & 6 & $\begin{array}{l}1.52 \\
(0.95-2.44)\end{array}$ & $p=0.04$ & \\
\hline$>3$ & 3 & $\begin{array}{l}2.31 \\
(1.20-4.43)\end{array}$ & $\mathrm{P}=0.01$ & & 1 & $\begin{array}{l}4.10 \\
(1.70-9.89)\end{array}$ & - & & 5 & $\begin{array}{l}3.00 \\
(1.48-6.12)\end{array}$ & $p=0.08$ & \\
\hline
\end{tabular}

Abbreviations: NLR: Neutrophil to lymphocyte ratio; NAC: neoadjuvant chemotherapy; OR: odds ratio; HR: hazard ratios; CI: confidence interval; pCR: pathological complete response; OS: overall survival; CSS: cancer special survival; DFS: disease-free survival; RFS: recurrence-free survival; Phet: pvalue for heterogeneity

\section{Discussion}

The NLR has been used as a systematic marker of inflammation and has garnered the interest of physicians in recent years. The prognostic significance of the NLR has been demonstrated by many meta-analyses in almost all tumour types[48] as well as in select tumour stages[49]. Some studies have explored the effect of the pretreatment NLR in cancer patients who received neoadjuvant chemotherapy, but the exact results are still undefined. In this meta-analysis, we included 33 studies and found that all studies were published within the past 6 years. Neoadjuvant chemotherapy was not given to patients with certain tumour types, and thus only 6 cancer types were eligible for our study, and among them, more than 2 studies were available for result pooling this only for bladder cancer, breast cancer, rectal cancer and gastroesophageal cancer. After all the relevant results were pooled, we found that a lower NLR was associated with a higher $\mathrm{pCR}$ rate and that a lower NLR served as a prognostic indicator, as it was associated with good OS, CSS, DFS and RFS.

The reason why an elevated NLR is associated with a lower $\mathrm{pCR}$ rate and worse outcomes is not completely understood. The most reasonable explanation is that the NLR is related to systematic inflammation in patients with tumours[50]. Host immune system and tumours interaction significantly associated with cancer patients' prognosis and measure some simple systemic immune reaction markers such as neutrophil, lymphocyte and NLR can generally represent the host-tumor interaction conditions[51, 52]. Neutrophils can produce some types of cytokines, such as transforming growth factor-beta and vascular endothelial growth factor especially after they integrated with cancer cells; this in turn leads to cancer cell proliferation, infiltration 
and metastasis[53-56]. In addition, blood neutrophils were found to inhibit the function of lymphocytes when co-incubated these two kind of cells, which may influence patients' immune system[57]. Lymphocytes, however, are known to play an important role in the suppression of cancer via the induction of cytotoxic cell death, and a higher pretreatment lymphocyte count was found to be associated with good neoadjuvant treatment response in patients with locally advanced rectal cancers[58]. The interaction between the immune system and cancer cells mostly occurs near the tumour tissue, and thus there may be some connection between the peripheral NLR and tumour-infiltrating lymphocytes. An increase in tumour-infiltrating lymphocytes has been shown to play a significant role in prognosis in many types of cancer such as breast cancer, lung cancer and gastric cancer[59-61].

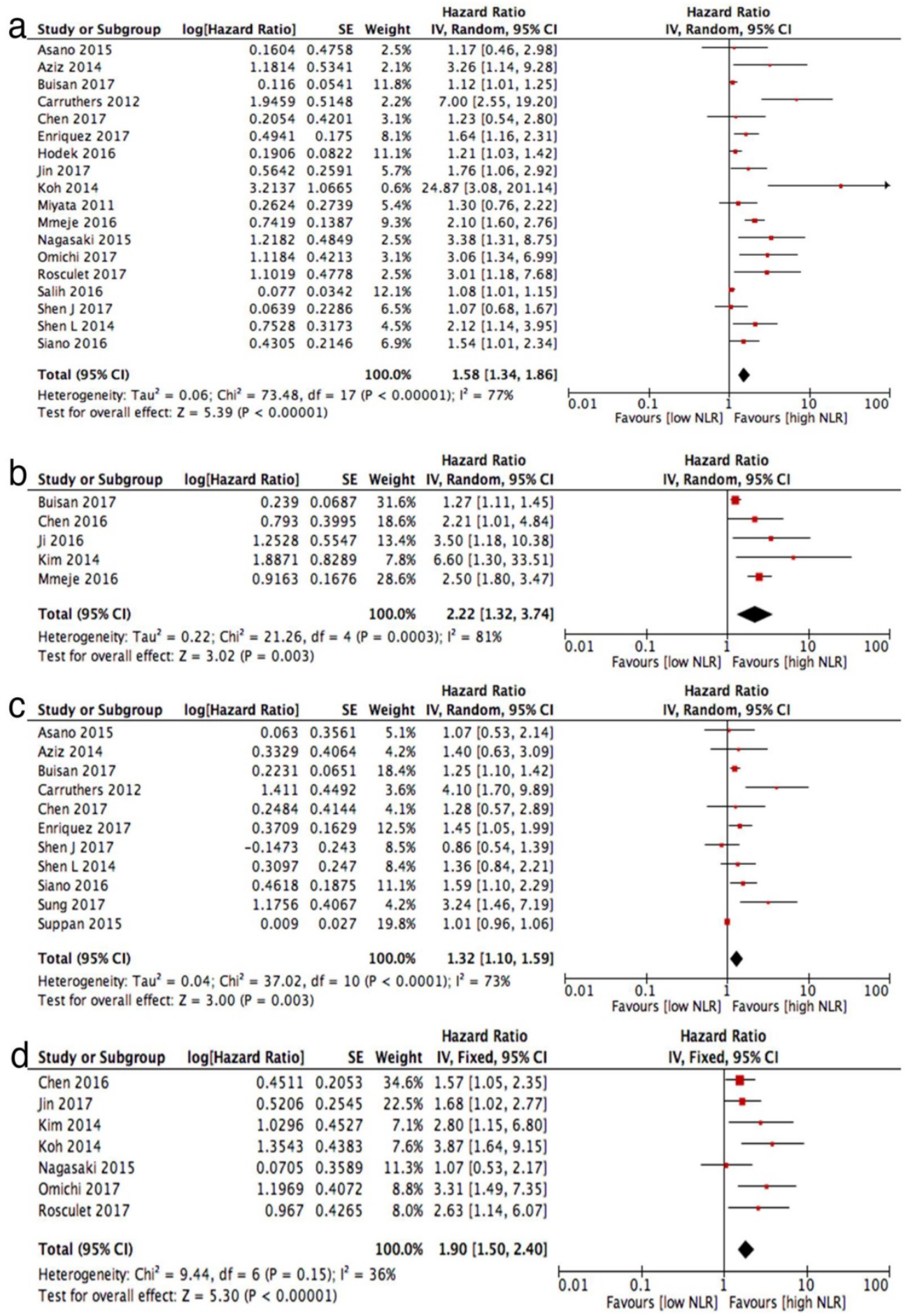

Figure 3. Forest plots for associations between NLR and (a) overall survival, (b) cancer special survival, (c) disease-free survival, (d) recurrence-free survival. 


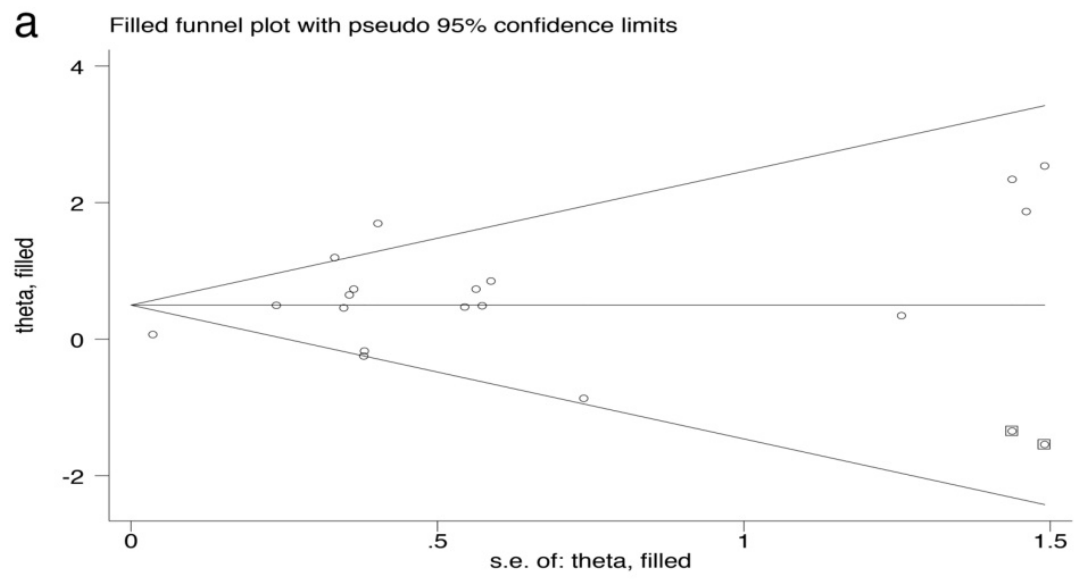

b Filled funnel plot with pseudo $95 \%$ confidence limits

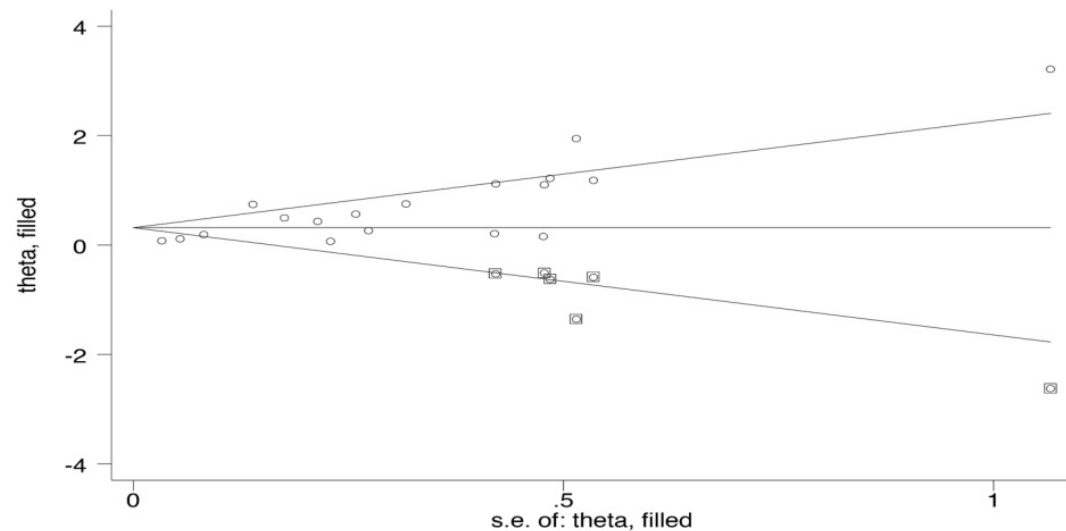

Figure 4. Funnel plot used trim-and-fill methods for (a) pathological complete response and (b) overall survival.

The effect of tumour-infiltrating lymphocytes was also found to be closely associated with neoadjuvant treatment response especially in breast cancer[62, 63]. Other studies have investigated the association between the NLR and circulating cytokines. Motomura and Kantola found that tumours with an elevated NLR also had higher levels of some interleukins and MCP-1, among other cytokines. This suggested that the NLR may partly influence the immune response[64, 65].

In this analysis, all bladder cancer patients were treated with neoadjuvant chemotherapy followed by radical cystectomy. A low pretreatment NLR was associated with a significant increase in the $\mathrm{pCR}$ rate and a longer DFS, but for OS, its protective effect was not statistically significant. Bladder cancer is thought to be an immune-related disease as it responds well to immunotherapy[66]. Many other immune-related markers such as lymphocyte-to-monocyte ratio (LMR), hemoglobin, platelet-to-lymphocyte ratio (PLR) were found to significantly associated with outcomes in bladder cancer patients but their research in neoadjuvant chemotherapy patients were few[67-70]. In a small sample retrospective study conducted by Seah, NLR were found to sustained decreased in NAC response patients, this decrease of inflammatory burden may associated with patients' pathological response[14]. Viers explored 899 bladder cancer patients and found that the NLR may be used as a prognostic marker for risk stratification including for the selection of patients who might benefit from neoadjuvant therapy[71]. The finding that the NLR did not show a statistically significant relationship with OS may be partly due to indelible heterogeneities such as tumor burden and invasive ranges.

The NLR seems not to be a good marker for patients with breast cancer who received neoadjuvant chemotherapy, as the pooled data for OS, DFS and pCR all did not appear to show significant differences. Although breast cancer is not generally regarded as an immune-related disease, a low NLR in unstratified breast cancer patients in previous studies was still found to be associated with good OS and DFS[72-74]. Marin retrospective 150 breast cancer patients and found some immune-related markers such as high lymphocyte-to-monocyte ratio (LMR) and low NLR were associated with favorable prognoses in patients treated with NAC[23]. The inconsistent results of the NLR in breast cancer may partly due to the different molecular subtypes of tumours. Yao and Asano reported that the NLR was a good prognostic marker in triple-negative breast cancer[15, 75], but Noh found that an elevated NLR was associated with a poorer disease-specific survival, which was evident mostly in the luminal A subtype[76]. The dominant molecular subtype in a cohort of breast cancer patients may obviously influence the prognostic effect of the NLR.

A low NLR was associated with a significantly higher $\mathrm{pCR}$ rate and a protective effect with respect to OS in rectal cancer patients who received pre-operative treatment. This may be attributed to a variety of reasons. On the one hand, colorectal cancer is found closely associated with systemic inflammation, as Guthrie found that several systemic inflammation-related markers exhibited prognostic value in colorectal cancer patients[77] and Burn discovered that long-term use of aspirin, a non-steroidal anti-inflammatory drug, can decrease the risk of colorectal cancer[78]. On the other hand, all the studies except one treated patients with neoadjuvant chemoradiation and compared them 
with patients who were treated only with neoadjuvant chemotherapy, which increased the chance of a $\mathrm{pCR}$ and a survival benefit would be achieved. However, the definitive effect of neoadjuvant radiation on patients with rectal cancer is still controversial. But other factors may challenge the use of NLR in rectal cancer just like Krauthamer found that NLR was an independent factor for CPR after neoadjuvant treatments in clinical stage (CS) III while not in clinical stage (CS) II locally advanced rectal cancers[39]. Except for tumour burden the low or high location may also influence the effect of NLR in rectal cancer but until now few articles definitely analyzed this field.

In gastroesophageal cancer, the association of the NLR and OS showed no statistical significance. In other types of tumours, the number of studies was limited to come to an exactly conclusion, which is a limitation of our meta-analysis. Our study has other limitations, which are discussed below. First, the studies enrolled in our analysis were mostly retrospective, and therefore, some individual data such as specific regimens and doses of neoadjuvant treatment were not considered. Second, publication bias still exists in our study, and although we chose to include all the data from full-text studies and abstracts and even used the trim-and-fill method to confirm our results, some negative data that were omitted by us may still have influenced the results. Third, the heterogeneity could not be fully eliminated in this analysis, examples include tumour stage, age distribution, and the cut-off value of the NLR, among others. Finally, the presence of other diseases in addition to cancer, such as coronary artery disease, hepatic disease, metabolic syndrome and any inflammation-related diseases, can alter the level of the NLR, which may have affected our results[79-81].

\section{Conclusions}

Our meta-analysis pooled 33 studies to assess the response rate and prognostic effect of the NLR in patients who received NAC. In summary, patients in many types of solid tumours who had an NLR lower than the cut-off values were more likely to achieve pCR after NAC. The NLR may serve as a convenient marker in patients who receive NAC with respect to survival outcome and prognosis, as a higher NLR indicates a worse survival outcome, including OS, CSS, DFS and RFS. NLR is a simply accessible and cost-effective prognostic marker that may identify high-risk patients with certain types of tumours. Further prospective studies with large sample sizes and suitable patients are needed to validate our results and to determine the consensus cut-off value of NLR for each cancer type.

\section{Abbreviations}

NLR: Neutrophil to lymphocyte ratio; NAC: neoadjuvant chemotherapy; OR: odds ratio; HR: hazard ratios; CI: confidence interval; pCR: pathological complete response; OS: overall survival; CSS: cancer special survival; DFS: disease-free survival; RFS: recurrence-free survival; NOS: Newcastle-Ottawa Scale

\section{Conflicts of interest}

The authors declare that they have no conflict of interest.

\section{References}

1. Abarbanel DN, Seki SM, Davies Y, Marlen N, Benavides JA, Cox K, et al. Immunomodulatory effect of vancomycin on Treg in pediatric inflammatory bowel disease and primary sclerosing cholangitis. Journal of clinical immunology. 2013; 33: 397-406.

2. Neoadjuvant chemotherapy in invasive bladder cancer: update of a systematic review and meta-analysis of individual patient data advanced bladder cancer (ABC) meta-analysis collaboration. European urology. 2005; 48: 202-5; discussion 5-6.

3. Wolmark N, Wang J, Mamounas E, Bryant J, Fisher B. Preoperative chemotherapy in patients with operable breast cancer: nine-year results from National Surgical Adjuvant Breast and Bowel Project B-18. Journal of the National Cancer Institute Monographs. 2001: 96-102.

4. Rosenblatt R, Sherif A, Rintala E, Wahlqvist R, Ullen A, Nilsson S, et al. Pathologic downstaging is a surrogate marker for efficacy and increased survival following neoadjuvant chemotherapy and radical cystectomy for muscle-invasive urothelial bladder cancer. European urology. 2012; 61: 1229-38.

5. Zargar H, Espiritu PN, Fairey AS, Mertens LS, Dinney CP, Mir MC, et al. Multicenter assessment of neoadjuvant chemotherapy for muscle-invasive bladder cancer. European urology. 2015; 67: 241-9.

6. Plimack ER, Dunbrack RL, Brennan TA, Andrake MD, Zhou Y, Serebriiskii IG, et al. Defects in DNA Repair Genes Predict Response to Neoadjuvant Cisplatin-based Chemotherapy in Muscle-invasive Bladder Cancer. European urology. 2015; 68: 959-67.

7. Groenendijk FH, de Jong J, Fransen van de Putte EE, Michaut M, Schlicker A, Peters D, et al. ERBB2 Mutations Characterize a Subgroup of Muscle-invasive Bladder Cancers with Excellent Response to Neoadjuvant Chemotherapy. European urology. 2016; 69: 384-8.

8. Grivennikov SI, Greten FR, Karin M. Immunity, inflammation, and cancer. Cell. 2010; 140: 883-99.

9. O'Callaghan DS, O'Donnell D, O'Connell F, O'Byrne KJ. The role of inflammation in the pathogenesis of non-small cell lung cancer. Journal of thoracic oncology : official publication of the International Association for the Study of Lung Cancer. 2010; 5: 2024-36.

10. Aggarwal BB, Vijayalekshmi RV, Sung B. Targeting inflammatory pathways for prevention and therapy of cancer: short-term friend, long-term foe. Clinical cancer research : an official journal of the American Association for Cancer Research. 2009; 15: 425-30.

11. van Verschuer VM, Hooning MJ, van Baare-Georgieva RD, Hollestelle A, Timmermans AM, Koppert LB, et al. Tumor-associated inflammation as a potential prognostic tool in BRCA1/2-associated breast cancer. Human pathology. 2015; 46: 182-90

12. Luo G, Guo M, Liu Z, Xiao Z, Jin K, Long J, et al. Blood neutrophil-lymphocyte ratio predicts survival in patients with advanced pancreatic cancer treated with chemotherapy. Annals of surgical oncology. 2015; 22: 670-6.

13. Guthrie GJK, Charles KA, Roxburgh CSD, Horgan PG, McMillan DC, Clarke SJ. The systemic inflammation-based neutrophil-lymphocyte ratio: Experience in patients with cancer. Critical Reviews in Oncology Hematology. 2013; 88: 218-30.

14. Seah J-A, Leibowitz-Amit R, Atenafu EG, Alimohamed N, Knox JJ, Joshua $\mathrm{AM}$, et al. Neutrophil-Lymphocyte Ratio and Pathological Response to Neoadjuvant Chemotherapy in Patients With Muscle-Invasive Bladder Cancer. Clinical genitourinary cancer. 2015; 13: E229-E33.

15. Asano Y, Kashiwagi S, Onoda N, Noda S, Kawajiri H, Takashima T, et al. Predictive Value of Neutrophil/Lymphocyte Ratio for Efficacy of Preoperative Chemotherapy in Triple-Negative Breast Cancer. Annals of surgical oncology. 2016; 23: 1104-10.

16. Buisan O, Orsola A, Areal J, Font A, Oliveira M, Martinez R, et al. Low Pretreatment Neutrophil-to-Lymphocyte Ratio Predicts for Good Outcomes in Patients Receiving Neoadjuvant Chemotherapy Before Radical Cystectomy for Muscle Invasive Bladder Cancer. Clinical genitourinary cancer. 2017; 15: 145-51.e2. 
17. van Kessel KE, de Haan LM, Fransen van de Putte EE, van Rhijn BW, de Wit R, van der Heijden MS, et al. Elevated Derived Neutrophil-to-Lymphocyte Ratio Corresponds With Poor Outcome in Patients Undergoing Pre-Operative Cancle-Invasive Bladder Cancer. Bladder cancer (Amsterdam, Netherlands). 2016; 2: 351-60.

18. Leibowitz-Amit R, Israel A, Gal M, Atenafu EA, Symon Z, Portnoy O, et al. Association between the Absolute Baseline Lymphocyte Count and Response to Neoadjuvant Platinum-based Chemotherapy in Muscle-invasive Bladder Cancer. Clinical oncology (Royal College of Radiologists (Great Britain)). 2016; 28: 790-6.

19. Mmeje CO, Slade A, Slack R, Naval N, Gao J, Siefker-Radtke AO, et al. The utility of neutrophil-to-lymphocyte ratio in determining survival outcomes in patients treated with neoadjuvant chemotherapy and radical cystectomy for high-risk bladder. Journal of Clinical Oncology. 2016; 34.

20. Kaiser J, Li H, Seah JA, Leibowitz-Amit R, North SA, Sridhar SS, et al. Baseline neutrophil to lymphocyte ratio as a prognostic marker for patients with muscle-invasive bladder cancer being treated with neoadjuvant chemotherapy. Journal of Clinical Oncology. 2016; 34.

21. Chen Y, Chen K, Xiao X, Nie Y, Qu S, Gong C, et al. Pretreatment neutrophil-to-lymphocyte ratio is correlated with response to neoadjuvant chemotherapy as an independent prognostic indicator in breast cancer patients: a retrospective study. BMC cancer. 2016; 16: 320.

22. Enriquez D, De la Cruz Ku GA, Fernandez M, Eyzaguirre E, Luque R, Paitan $\mathrm{D}$, et al. Predictive value of neutrophil-to-lymphocyte ratio on pathological complete response in triple negative breast cancer. Journal of Clinical Oncology. 2017; 35

23. Marin Hernandez C, Pinero Madrona A, Gil Vazquez PJ, Galindo Fernandez PI, Ruiz Merino G, Alonso Romero JL, et al. Usefulness of lymphocyte-to-monocyte, neutrophil-to-monocyte and neutrophil-to-lymphocyte ratios as prognostic markers in breast cancer patients treated with neoadjuvant chemotherapy. Clinical \& translational oncology : official publication of the Federation of Spanish Oncology Societies and of the National Cancer Institute of Mexico. 2017.

24. Koh YW, Lee HI, Ahn JH, Lee JW, Gong G. Prognostic significance of the ratio of absolute neutrophil to lymphocyte counts for breast cancer patients with ER/PR-positivity and HER2-negativity in neoadjuvant setting. Tumour biology : the journal of the International Society for Oncodevelopmental Biology and Medicine. 2014; 35: 9823-30.

25. McGuire A, Haris A, Curran C, Brown JAL, Kerin MJ. To assess the ability of pre-operative NLR scores to predict response to neo-adjuvant chemotherapy in breast cancer. Irish Journal of Medical Science. 2017; 186: S119.

26. Suppan C, Bjelic-Radisic V, La Garde M, Groselj-Strele A, Eberhard K, Samonigg $\mathrm{H}$, et al. Neutrophil/Lymphocyte ratio has no predictive or prognostic value in breast cancer patients undergoing preoperative systemic therapy. BMC cancer. 2015; 15: 1027.

27. Xu J, Ni C, Ma C, Zhang L, Jing X, Li C, et al. Association of neutrophil/lymphocyte ratio and platelet/lymphocyte ratio with ER and PR in breast cancer patients and their changes after neoadjuvant chemotherapy. Clinical \& translational oncology : official publication of the Federation of Spanish Oncology Societies and of the National Cancer Institute of Mexico. 2017; 19: 989-96.

28. Caputo D, Caricato M, Coppola A, La Vaccara V, Fiore M, Coppola R Neutrophil to Lymphocyte Ratio (NLR) and Derived Neutrophil to Lymphocyte Ratio (d-NLR) Predict Non-Responders and Postoperative Complications in Patients Undergoing Radical Surgery After Neo-Adjuvant Radio-Chemotherapy for Rectal Adenocarcinoma. Cancer investigation. 2016: 1-12.

29. Carruthers R, Tho LM, Brown J, Kakumanu S, McCartney E, McDonald AC. Systemic inflammatory response is a predictor of outcome in patients undergoing preoperative chemoradiation for locally advanced rectal cancer. Colorectal disease : the official journal of the Association of Coloproctology of Great Britain and Ireland. 2012; 14: e701-7.

30. Dudani S, Marginean H, Tang PA, Monzon JG, Raissouni S, Asmis TR, et al. Neutrophil-to-lymphocyte and platelet-to-lymphocyte ratios as predictive and prognostic markers in patients with locally advanced rectal cancer treated with neoadjuvant chemoradiation. Journal of Clinical Oncology. 2017; 35

31. Hodek M, Sirak I, Ferko A, Orhalmi J, Hovorkova E, Hadzi Nikolov D, et al. Neoadjuvant chemoradiotherapy of rectal carcinoma : Baseline hematologic parameters influencing outcomes. Strahlentherapie und Onkologie : Organ der Deutschen Rontgengesellschaft [et al]. 2016; 192: 632-40.

32. Lee IH, Hwang S, Lee SJ, Kang BW, Baek D, Kim HJ, et al. Systemic Inflammatory Response After Preoperative Chemoradiotherapy Can Affect Oncologic Outcomes in Locally Advanced Rectal Cancer. Anticancer research. 2017; 37: 1459-65.

33. Nagasaki T, Akiyoshi T, Fujimoto $Y$, Konishi T, Nagayama S, Fukunaga $Y$, et al. Prognostic Impact of Neutrophil-to-Lymphocyte Ratio in Patients with Advanced Low Rectal Cancer Treated with Preoperative Chemoradiotherapy. Digestive surgery. 2015; 32: 496-503.

34. Runau F, Collins A, Fenech GA, Ford E, Dimitriou N, Chaudhri S, et al A single institution's long-term follow-up of patients with pathological complete response in locally advanced rectal adenocarcinoma following neoadjuvant chemoradiotherapy. International journal of colorectal disease. 2017; 32: 341-8.

35. Shen J, Zhu Y, Wu W, Zhang L, Ju H, Fan Y, et al. Prognostic Role of Neutrophil-to-Lymphocyte Ratio in Locally Advanced Rectal Cancer Treated with Neoadjuvant Chemoradiotherapy. Medical science monitor : international medical journal of experimental and clinical research. 2017; 23: 315-24.

36. Shen $\mathrm{L}$, Zhang $\mathrm{H}$, Liang $\mathrm{L}$, Li G, Fan $\mathrm{M}$, Wu $\mathrm{Y}$, et al. Baseline neutrophil-lymphocyte ratio $(>/=2.8)$ as a prognostic factor for patients with locally advanced rectal cancer undergoing neoadjuvant chemoradiation. Radiation oncology (London, England). 2014; 9: 295.

37. Sung S, Son SH, Park EY, Kay CS. Prognosis of locally advanced rectal cancer can be predicted more accurately using pre- and post-chemoradiotherapy neutrophil-lymphocyte ratios in patients who received preoperative chemoradiotherapy. PloS one. 2017; 12: e0173955.

38. Kim IY, You SH, Kim YW. Neutrophil-lymphocyte ratio predicts pathologic tumor response and survival after preoperative chemoradiation for rectal cancer. BMC surgery. 2014; 14: 94

39. Krauthamer M, Rouvinov K, Ariad S, Man S, Walfish S, Pinsk I, et al. A study of inflammation-based predictors of tumor response to neoadjuvant chemoradiotherapy for locally advanced rectal cancer. Oncology. 2013; 85: 27-32

40. Abd el Aziz LM. Blood neutrophil-lymphocyte ratio predicts survival in locally advanced cancer stomach treated with neoadjuvant chemotherapy FOLFOX 4. Medical Oncology. 2014; 31.

41. Chen L, Zuo Y, Zhu L, Zhang Y, Li S, Ma F, et al. Peripheral venous blood neutrophil-to-lymphocyte ratio predicts survival in patients with advanced gastric cancer treated with neoadjuvant chemotherapy. OncoTargets and therapy. 2017; 10: 2569-80.

42. Jin H, Sun J, Zhu K, Liu X, Zhang Q, Shen Q, et al. The prognostic value of neutrophil-lymphocyte ratio is superior to derived neutrophil-lymphocyte ratio in advanced gastric cancer treated with preoperative chemotherapy and equential R0 resection: a 5-year follow-up. OncoTargets and therapy. 2017; 10: $2655-64$

43. Ji WH, Jiang YH, Ji YL, Li B, Mao WM. Prechemotherapy neutrophil lymphocyte ratio is superior to the platelet : lymphocyte ratio as a prognostic indicator for locally advanced esophageal squamous cell cancer treated with neoadjuvant chemotherapy. Diseases of the esophagus : official journal of the International Society for Diseases of the Esophagus. 2016; 29: 403-11.

44. Miyata H, Yamasaki M, Kurokawa Y, Takiguchi S, Nakajima K, Fujiwara Y, et al. Prognostic value of an inflammation-based score in patients undergoing pre-operative chemotherapy followed by surgery for esophageal cancer. Experimental and Therapeutic Medicine. 2011; 2: 879-85.

45. Salih Z, Papaxoinis G, Conway A, Patrao ASJ, Fletcher K, Noble R, et al. Prognostic significance of neutrophil to lymphocyte ratio (NLR) in patients with respectable oesophageal/gastroesophageal junction (O/GOJ) adenocarcinoma undergoing perioperative chemotherapy. Journal of Clinical Oncology. 2016; 34.

46. Rosculet N, Zhou XC, Ha P, Tang M, Levine MA, Neuner G, et al. Neutrophil-to-lymphocyte ratio: Prognostic indicator for head and neck squamous cell carcinoma. Head and Neck-Journal for the Sciences and Specialties of the Head and Neck. 2017; 39: 662-7.

47. Omichi K, Cloyd JM, Yamashita S, Tzeng CD, Conrad C, Chun YS, et al. Neutrophil-to-lymphocyte ratio predicts prognosis after neoadjuvant chemotherapy and resection of intrahepatic cholangiocarcinoma. Surgery. 2017; 162: 752-65.

48. Templeton AJ, McNamara MG, Seruga B, Vera-Badillo FE, Aneja P, Ocana A, et al. Prognostic role of neutrophil-to-lymphocyte ratio in solid tumors: a systematic review and meta-analysis. Journal of the National Cancer Institute. 2014; 106: dju124.

49. Mei Z, Shi L, Wang B, Yang J, Xiao Z, Du P, et al. Prognostic role of pretreatment blood neutrophil-to-lymphocyte ratio in advanced cancer survivors: A systematic review and meta-analysis of 66 cohort studies. Cancer treatment reviews. 2017; 58: 1-13.

50. Gomez D, Morris-Stiff G, Toogood GJ, Lodge JP, Prasad KR. Impact of systemic inflammation on outcome following resection for intrahepatic cholangiocarcinoma. Journal of surgical oncology. 2008; 97: 513-8.

51. Ku JH, Kang M, Kim HS, Jeong CW, Kwak C, Kim HH. The prognostic value of pretreatment of systemic inflammatory responses in patients with urothelial carcinoma undergoing radical cystectomy. British journal of cancer. 2015; 112: $461-7$

52. Paik KY, Lee IK, Lee YS, Sung NY, Kwon TS. Clinical implications of systemic inflammatory response markers as independent prognostic factors in colorectal cancer patients. Cancer research and treatment : official journal of Korean Cancer Association. 2014; 46: 65-73.

53. Tsushima H, Kawata S, Tamura S, Ito N, Shirai Y, Kiso S, et al. High levels of transforming growth factor beta 1 in patients with colorectal cancer: association with disease progression. Gastroenterology. 1996; 110: 375-82

54. Elliott RL, Blobe GC. Role of transforming growth factor Beta in human cancer. Journal of clinical oncology : official journal of the American Society of Clinical Oncology. 2005; 23: 2078-93.

55. Calon A, Tauriello DV, Batlle E. TGF-beta in CAF-mediated tumor growth and metastasis. Seminars in cancer biology. 2014; 25: 15-22.

56. Kusumanto $\mathrm{YH}$, Dam WA, Hospers GA, Meijer C, Mulder NH. Platelets and granulocytes, in particular the neutrophils, form important compartments for circulating vascular endothelial growth factor. Angiogenesis. 2003; 6: 283-7.

57. Petrie HT, Klassen LW, Kay HD. Inhibition of human cytotoxic T lymphocyte activity in vitro by autologous peripheral blood granulocytes. Journal of immunology (Baltimore, Md : 1950). 1985; 134: 230-4. 
58. Choi CH, Kim WD, Lee SJ, Park WY. Clinical predictive factors of pathologic tumor response after preoperative chemoradiotherapy in rectal cancer. Radiation oncology journal. 2012; 30: 99-107.

59. Geng Y, Shao Y, He W, Hu W, Xu Y, Chen J, et al. Prognostic Role of Tumor-Infiltrating Lymphocytes in Lung Cancer: a Meta-Analysis. Cellular physiology and biochemistry : international journal of experimental cellular physiology, biochemistry, and pharmacology. 2015; 37: 1560-71.

60. Mao Y, Qu Q, Chen X, Huang O, Wu J, Shen K. The Prognostic Value of Tumor-Infiltrating Lymphocytes in Breast Cancer: A Systematic Review and Meta-Analysis. PloS one. 2016; 11: e0152500.

61. Zheng $\mathrm{X}$, Song $\mathrm{X}$, Shao $\mathrm{Y}, \mathrm{Xu} \mathrm{B}$, Chen $\mathrm{L}$, Zhou Q, et al. Prognostic role of tumor-infiltrating lymphocytes in gastric cancer: a meta-analysis. Oncotarget. 2017; 8: 57386-98.

62. Melichar B, Studentova $\mathrm{H}$, Kalabova $\mathrm{H}$, Vitaskova $\mathrm{D}$, Cermakova $\mathrm{P}$ Hornychova $\mathrm{H}$, et al. Predictive and prognostic significance of tumor-infiltrating lymphocytes in patients with breast cancer treated with neoadjuvant systemic therapy. Anticancer research. 2014; 34: 1115-25.

63. Denkert C, von Minckwitz G, Brase JC, Sinn BV, Gade S, Kronenwett R, et al. Tumor-infiltrating lymphocytes and response to neoadjuvant chemotherapy with or without carboplatin in human epidermal growth factor receptor 2-positive and triple-negative primary breast cancers. Journal of clinical oncology : official journal of the American Society of Clinical Oncology. 2015; 33: 983-91.

64. Motomura T, Shirabe K, Mano Y, Muto J, Toshima T, Umemoto Y, et al. Neutrophil-lymphocyte ratio reflects hepatocellular carcinoma recurrence after liver transplantation via inflammatory microenvironment. Journal of Hepatology. 2013; 58: 58-64.

65. Kantola T, Klintrup K, Vayrynen JP, Vornanen J, Bloigu R, Karhu T, et al. Stage-dependent alterations of the serum cytokine pattern in colorectal carcinoma. British journal of cancer. 2012; 107: 1729-36.

66. Powles T, Eder JP, Fine GD, Braiteh FS, Loriot Y, Cruz C, et al. MPDL3280A (anti-PD-L1) treatment leads to clinical activity in metastatic bladder cancer. Nature. 2014; 515: 558-62

67. Bhindi B, Hermanns T, Wei Y, Yu J, Richard PO, Wettstein MS, et al. Identification of the best complete blood count-based predictors for bladder cancer outcomes in patients undergoing radical cystectomy. British journal of cancer. 2016; 114: 207-12.

68. Gierth M, Mayr R, Aziz A, Krieger S, Wullich B, Pycha A, et al. Preoperative anemia is associated with adverse outcome in patients with urothelial carcinoma of the bladder following radical cystectomy. Journal of cancer research and clinical oncology. 2015; 141: 1819-26.

69. Temraz S, Mukherji D, Farhat ZA, Nasr R, Charafeddine M, Shahait M, et al. Preoperative lymphocyte-to-monocyte ratio predicts clinical outcome in patients undergoing radical cystectomy for transitional cell carcinoma of the bladder: a retrospective analysis. BMC urology. 2014; 14: 76.

70. Schulz GB, Grimm T, Buchner A, Jokisch F, Grabbert M, Schneevoigt BS, et al. Prognostic Value of the Preoperative Platelet-to-leukocyte Ratio for Oncologic Outcomes in Patients Undergoing Radical Cystectomy for Bladder Cancer. Clinical genitourinary cancer. 2017.

71. Viers BR, Boorjian SA, Frank I, Tarrell RF, Thapa P, Karnes RJ, et al. Pretreatment neutrophil-to-lymphocyte ratio is associated with advanced pathologic tumor stage and increased cancer-specific mortality among patients with urothelial carcinoma of the bladder undergoing radical cystectomy. European urology. 2014; 66: 1157-64.

72. Liu X, Qu JK, Zhang J, Yan Y, Zhao XX, Wang JZ, et al. Prognostic role of pretreatment neutrophil to lymphocyte ratio in breast cancer patients: A meta-analysis. Medicine. 2017; 96: e8101.

73. Chen I, Deng $Q$, Pan $Y$, He B, Ying H, Sun $H$, et al. Prognostic value of neutrophil-to-lymphocyte ratio in breast cancer. FEBS open bio. 2015; 5: 502-7.

74. Ethier JL, Desautels D, Templeton A, Shah PS, Amir E. Prognostic role of neutrophil-to-lymphocyte ratio in breast cancer: a systematic review and meta-analysis. Breast cancer research : BCR. 2017; 19: 2.

75. Yao M, Liu Y, Jin H, Liu X, Lv K, Wei H, et al. Prognostic value of preoperative inflammatory markers in Chinese patients with breast cancer. OncoTargets and therapy. 2014; 7: 1743-52.

76. Noh H, Eomm M, Han A. Usefulness of pretreatment neutrophil to lymphocyte ratio in predicting disease-specific survival in breast cancer patients. J Breast Cancer. 2013; 16: 55-9.

77. Guthrie GJ, Roxburgh CS, Farhan-Alanie OM, Horgan PG, McMillan DC Comparison of the prognostic value of longitudinal measurements of systemic inflammation in patients undergoing curative resection of colorectal cancer. British journal of cancer. 2013; 109: 24-8.

78. Burn J, Gerdes AM, Macrae F, Mecklin JP, Moeslein G, Olschwang S, et al. Long-term effect of aspirin on cancer risk in carriers of hereditary colorectal cancer: an analysis from the CAPP2 randomised controlled trial. Lancet. 2011; 378: 2081-7.

79. Tamhane UU, Aneja S, Montgomery D, Rogers EK, Eagle KA, Gurm HS. Association between admission neutrophil to lymphocyte ratio and outcomes in patients with acute coronary syndrome. The American journal of cardiology. 2008; 102: 653-7.

80. Balta S, Cakar M, Demirkol S, Arslan Z, Akhan M. Higher neutrophil to lymhocyte ratio in patients with metabolic syndrome. Clinical and applied thrombosis/hemostasis : official journal of the International Academy of Clinical and Applied Thrombosis/Hemostasis. 2013; 19: 579.
81. Biyik M, Ucar R, Solak Y, Gungor G, Polat I, Gaipov A, et al. Blood neutrophil-to-lymphocyte ratio independently predicts survival in patients with liver cirrhosis. Eur J Gastroenterol Hepatol. 2013; 25: 435-41. 